\title{
Vascular supply of the central nervous system of the land snail Megalobulimus oblongus (Gastropoda, Pulmonata)
}

H.G. Nóblega ${ }^{1,2}$,

V. Missaglia' ${ }^{1,2}$, C. Stenert ${ }^{1,2}$,

M.C. Faccioni-Heuser ${ }^{1}$ and M. Achaval ${ }^{1}$
${ }^{1}$ Laboratório de Histofisiologia Comparada, Departamento de Ciências Morfológicas, Instituto de Ciências Básicas da Saúde, Universidade Federal do Rio Grande do Sul, Porto Alegre, RS, Brasil

${ }^{2}$ Laboratório de Anatomia, Centro de Ciências da Saúde,

Universidade do Vale do Rio dos Sinos, São Leopoldo, RS, Brasil
Correspondence

M. Achaval

Laboratório de Histofisiologia

Comparada

Departamento de Ciências

Morfológicas, ICBS, UFRGS

Rua Sarmento Leite, 500

90050-170 Porto Alegre, RS

Brasil

Fax: +55-51-3316-3092

E-mail: achaval@ufrgs.br

Presented at the XV Annual Meeting of the Federação de Sociedades de Biologia Experimental, Caxambu, MG, Brazil, August 23-26, 2000

Research partially supported by FINEP, CAPES, CNPq and UNISINOS.

Received June 14, 2002

Accepted May 27, 2003

\begin{abstract}
The vascularization of the central nervous system of the snail Megalobulimus oblongus was studied by injection of carmine-gelatin solution into the arterial system and using a histochemical technique for the detection of alkaline phosphatase. The central nervous system of $M$. oblongus is irrigated by the anterior aorta, from which a series of small branches emerge that supply the subesophageal nervous ganglia. In turn, these branches give rise to a series of smaller vessels that irrigate the buccal bulb, the anterior portion of the foot, the cerebral ganglia, the dorsal body gland, and the anterior portion of the reproductive system. No hemolymph vessels were detected within nervous tissue although such vessels were found in the periganglionic connective sheath. This connective sheath contains vascular loops and had a series of overlaps and projections that follow the contour of the nervous ganglia. This arrangement permits a larger area of interaction between the surface of the nervous tissue and the hemolymph and reduces the distance between the deepest portion of a given ganglion and the hemolymph vessels.
\end{abstract}

Key words

- Gastropods

- Central nervous system

- Vascular supply

- Trypan blue

- Carmine-gelatin

- Alkaline phosphatase activity

\section{Introduction}

The vascular system of mollusks can be either open, as in the majority of species, or closed, as in the cephalopods. In gastropods this system, in addition to performing transport functions (1), plays a hydraulic role in the extension of the foot (2).

In the pulmonate gastropods, the hemolymph is pumped by the heart to the aorta, from which the caudal and cephalic branches originate. The cephalic branch is responsible for the hemolymph supply to the central nervous system (CNS). In these animals vessels, sinuses or lacunas are restricted to the periganglionic connective sheath, and no vessels are present within the ganglia (3).

The CNS of Megalobulimus oblongus is similar to that of Helix pomatia and other species of pulmonates (4). It consists of a periesophageal ring in which a pair of cerebral ganglia is interconnected by means of cerebral-pedal and cerebral-pleural connectives, a subesophageal ring formed of pairs of pedal, parietal and pleural ganglia and a single visceral ganglion. Two more distally 
located buccal ganglia are connected to the periesophageal ring by a pair of cerebralbuccal connectives (5).

A detailed description of the circulatory system requires a detailed understanding of the homeostasis and the general behavior of the animal (1). Knowledge of the vascularization of the nervous system is necessary in order to ascertain the nature of the existing neural-hemal interactions and the role played by the cardiovascular system (for a more detailed discussion, see Ref. 1).

The aim of the present study was to determine which vessels are responsible for the vascular supply and how this microvascularization occurs in the CNS of M. oblongus.

\section{Material and Methods}

Adult Stylommatophora snails of the species Megalobulimus oblongus (Müller, 1774; 60-75 g), from the county of Charqueadas in the State of Rio Grande do Sul, Brazil, were used. Fifteen animals were anesthetized by immersion in a menthol-saturated solution for 30 to $45 \mathrm{~min}$. After partial removal from the shell, the mantle and pericardium were sectioned, and the heart cannulated. The vascular tree was then washed with $M$. oblongus physiological saline solution (MPS) (6) and later injected with 2 to $3 \mathrm{ml}$ of carminegelatin solution (7). The animals were then fixed in Baker's formalin solution for a minimum of $24 \mathrm{~h}$ and later dissected with the aid of a stereomicroscope (STEMI SV11, Zeiss, Jena, Germany). Schematic representations of the vessel network related to the CNS ganglia of the snail were then prepared. Once the anatomical study was completed, the ganglia and vessels were cryoprotected in both 15 and $30 \%$ sucrose solutions, diluted in $0.1 \mathrm{M}$ phosphate buffer (PB), pH 7.4. Serial sections $(50 \mu \mathrm{m})$ were obtained with a cryostat (Leitz 1720, Wetzlar, Germany), mounted on slides, covered with glyceringelatin and coverslips and then observed and photographed under a light microscope
(Nikon Optiphot II, Tokyo, Japan).

Eight animals were injected into the pedal musculature with $2 \%$ Trypan blue diluted in MPS. The total volume $(50 \mu \mathrm{l} / \mathrm{g})$ was achieved by 5 injections applied at 15-min intervals. Animals were anesthetized and sacrificed 2, 3, 4, 5, 6 and $48 \mathrm{~h}$ after the last injection and CNS removal. The CNS was fixed in 4\% paraformaldehyde diluted in PB. After fixation, horizontal sections were obtained from the cerebral ganglia and the subesophageal ganglia using razor blades and the section surface was examined with a stereomicroscope (STEMI SV11, Zeiss).

Another group of five animals was used to demonstrate alkaline phosphatase activity. Two specimens were previously injected with carmine-gelatin solution as described above. The CNS was fixed in $4 \%$ paraformaldehyde diluted in PB and cryoprotected in 15 and $30 \%$ sucrose solutions, and $40-\mu \mathrm{m}$ sections were obtained with a cryostat (Leitz). Alkaline phosphatase activity was determined by incubating the tissue for $2 \mathrm{~h}$ at $37^{\circ} \mathrm{C}$ in a medium containing sodium $\beta-$ glycerophosphate (Sigma, St. Louis, MO, USA) as substrate. The material was then immersed in $2 \%$ cobalt chloride for $5 \mathrm{~min}$, washed and developed in a 5\% ammonium sulfide solution for $3 \mathrm{~min}$. A control was obtained by omitting the substrate from the incubation medium (8). The sections were mounted on slides and covered with glycerin-gelatin and coverslips.

\section{Results}

The snails injected with carmine-gelatin solution had a short common aorta that, after emerging from the heart, followed a brief right, lateral-posterior trajectory, after which it gave rise to the caudal and cephalic aortas. The proximal portion of the caudal aorta touched the surface of the hepatopancreas, burying itself within the most distal glandular tissue. The cephalic aorta originated from a posterior position in relation to the caudal 
branch. The proximal portion of the cephalic aorta extended in a dorsal-ventral direction and was enveloped by the hepatopancreas in its initial portion. Ventrally, it was located to the right of the median plane, from where it took a cephalic trajectory, maintaining a medial position in relation to the reproductive system, with which it kept close contact. The distal segment of the anterior aorta, after a short trajectory under the ventral surface of the right visceral and parietal ganglia, inflected in a dorsal direction, crossing the subesophageal ring, and finally divided into four branches (Figure 1). Under the ventral surface of the same segment of the cephalic aorta, four small diameter vessels emerged and supplied the subesophageal ganglia.

Of the four branches that arise from the anterior aorta, two are medial and two are lateral. When the animal retracts itself, the medial anterior branch curves ventrally, following the anterior edge of the pedal ganglia and extends towards the foot. The other medial branch is the ventral-buccal artery and displays the highest degree of consistency in relation to its point of origin and trajectory. This artery is responsible for the vascularization of the buccal bulb.

The two lateral branches that follow the cerebral-pleural and cerebral-pedal connectives run in a ventral-dorsal direction when the animal retracts itself. From each lateral branch emerge one or two small diameter arteries, the cerebral arteries. These bury themselves in the connective sheath and envelop the cerebral ganglia and the dorsal body gland. After the emergence of the cerebral arteries, the lateral branches divide again, giving rise to the tentacular arteries (Figures 1 and 2A), and the right lateral branch also gives rise to the branches that supply the anterior portion of the reproductive system.

Upon penetrating the connective sheath that envelops the cerebral ganglia, the cerebral arteries branch several times, giving rise to vessels of ever smaller diameter. The primary branches of the cerebral artery supply the hemolymph to the dorsal body gland, where a vast network of capillary vessels is found. Several vessels filled with carminegelatin solution were observed within the connective sheath. Of particular note was one large vascular space, located at the limit with the nervous tissue that enveloped the cerebral ganglia. A similar space was also

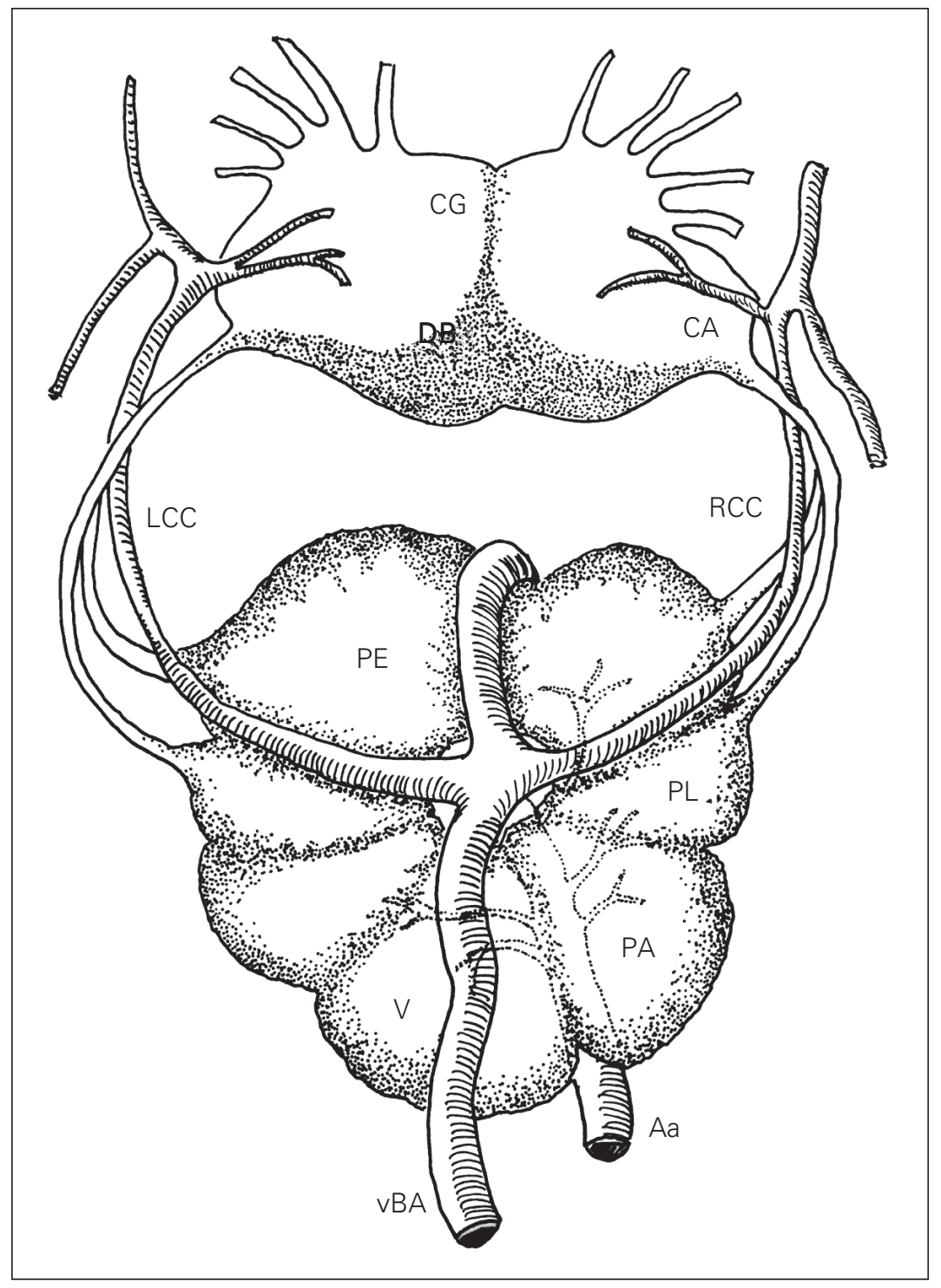

Figure 1. Schematic representation of the periesophageal ring and the vascular supply of the different central nervous ganglia in a posterodorsal view. The anterior aorta in its run ventral to the subesophageal ganglia is represented by a discontinuous line. Aa, anterior aorta; CA, cerebral artery; CG, cerebral ganglion; DB, dorsal body gland; LCC, left cervicalcephalic artery; $\mathrm{PA}$, parietal ganglion; $\mathrm{PE}$, pedal ganglion; $\mathrm{PL}$, pleural ganglion; $\mathrm{RCC}$, right cervical-cephalic artery; $\vee$, visceral ganglion; vBA, ventral-buccal artery. 
Figure 2. A, Dorsal view of the cerebral ganglia and buccal bulb. Note the vessels filled with carmine-gelatin (arrowheads). Bar = $2 \mathrm{~mm}$. B, Photomicrograph of a horizontal section of the cerebral ganglion after carmine-gelatin injection through the circulatory system. The limit where the vessels are located is identified by a discontinuous line. Bar = $0.5 \mathrm{~mm}$. B, buccal bulb; CA, cerebral artery; CC, cerebral commissure; CG, cerebral ganglia; DB, dorsal body gland.
Figure 3. Photomicrograph of the interface region (discontinuous line) between the nervous tissue and the connective sheath (CS). Note the intense alkaline phosphatase activity through the nervous tissue (arrowheads). Observe the imbricate relationship between the nervous tissue and the connective sheath where the negative hemolymph vessels (arrows) are housed. $\mathrm{Ne}$, neurons. Bar $=100$ $\mu \mathrm{m}$. observed between the glandular tissue of the dorsal body and the nervous tissue itself (Figure 2B).

The examination of the subesophageal ring indicated a relation similar to that described above for the vessels, connective sheath and nervous tissue. Here, as also observed for the cerebral ganglia, there was a
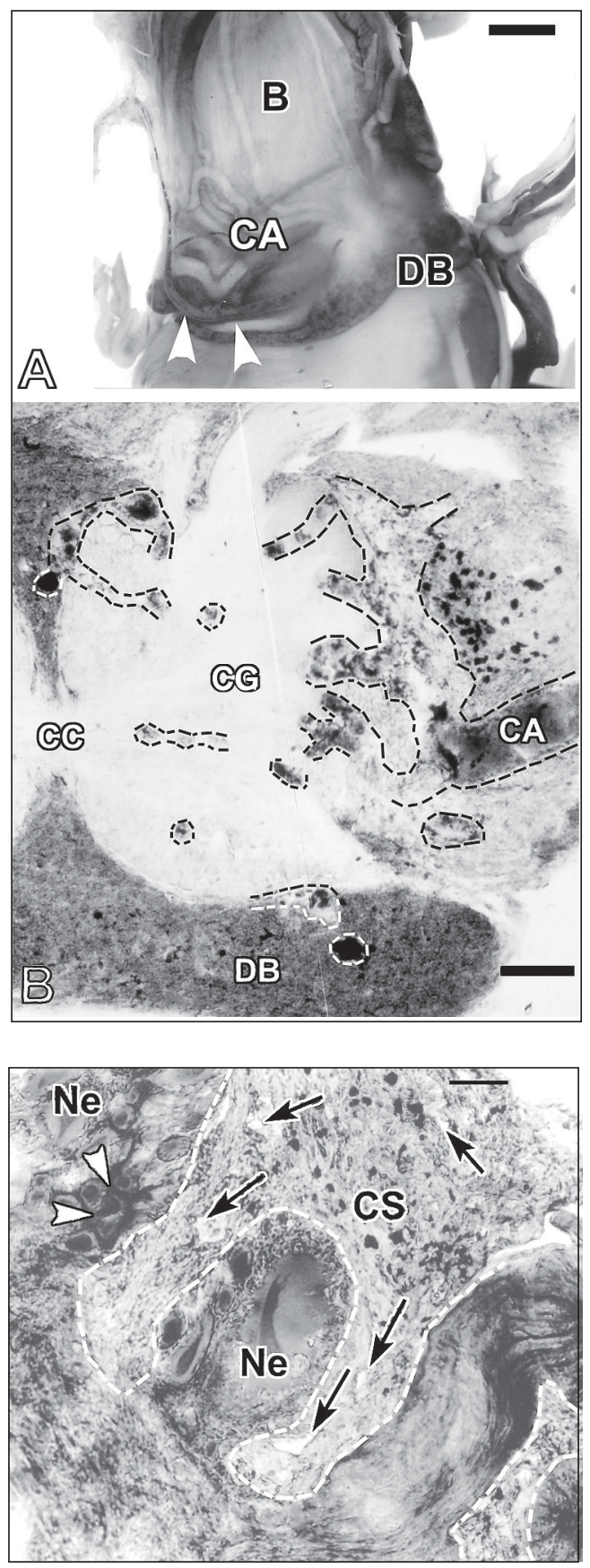

large vascular space that bordered the mass of nervous tissue. However, it should be noted that the supply to the subesophageal nerve ring originates from the small branches that emerge directly from the cephalic aorta and, after a brief trajectory, penetrate the connective tissue.

All the ganglia that constitute the periesophageal ring were penetrated by projections of the connective sheath of variable thickness. These connective projections were crossed by vessels of various diameters that were located close to the edges of the nervous tissue. Near the large diameter neurons, the overlaps appeared to be deeper and the vascularization more profuse (Figure 3 ).

The blood vessels present in the periganglionic connective sheath of buccal ganglia received hemolymph from a pair of arteries that emerged from a common branch originating from the middle portion of the anterior aorta. These arteries followed the salivary glands and their ducts until they reached the buccal ganglia located on the wall behind the buccal bulb, lateral-ventral to the esophageal connection.

The nervous tissue of $M$. oblongus only showed alkaline phosphatase activity in the perineuronal regions.

In the animals injected with Trypan blue, the dye reached the periganglionic connective sheath and the dorsal body gland, but was not found within the nervous tissue.

\section{Discussion}

There are a number of similarities between the vascular network of the CNS of $M$. oblongus and that of other species of Stylommatophora gastropod pulmonates. Comparison of the vascular arrangement of the CNS of M. oblongus and the vascularization of the central nervous ganglia in Helix pomatia reveals a high degree of similarity. In both species the anterior aorta makes contact with the subesophageal ring ventrally, between the right visceral and parietal gan- 
glia. After reaching the dorsal surface of the subesophageal ganglia it gives rise to a branch that is responsible for supplying the buccal bulb arteries that go to the foot (sometimes differing in number). Finally, a pair of lateral arteries (right and left) gives rise to the cerebral arteries that carry the hemolymph supply to the cerebral ganglia. As in M. oblongus, the subesophageal nerve ring of $H$. pomatia also receives irrigation from branches that originate directly from the aorta, though in this species they approach the ganglia from the dorsal surface (9).

The anatomical organization of the vessels responsible for the irrigation of the CNS in $M$. oblongus is similar to that found in Strophocheilus lorentzianus (10), a species of the same genus. In other Stylommatophora species such as Deroceras reticulatum, D. caruanae, Limax pseudoflavus, Milax budapestensis, Arion ater ater and A. hortensis (11) there are four branches that originate from the anterior aorta, three of which have a range similar to that found in $M$. oblongus. However, the structures supplied by these arteries are not necessarily the same as those that were found in this study. A fourth branch, the dorsal-buccal artery, was not found in $M$. oblongus. Two lateral arteries are responsible for the irrigation of the cerebral ganglia and subesophageal nerve ring. Invariably, in these species, the right lateral artery supplies the right cerebral ganglion and the subesophageal nervous ganglionic ring on the same side, and give rise to the right labial and tentacular arteries. The left branch, responsible for the left side of the CNS, also gives rise to pedal-penial and ventral-buccal arteries. This differs from the distribution observed in M. oblongus, especially with respect to the origin of the vessels responsible for the vascular supply to the set of subesophageal nervous ganglia and in relation to the emergence of the artery of the penis and ventral-buccal artery.

There is also some similarity between the anatomical organization of the arterial net- work that supplies the central ganglia of Basommatophora such as Lymnaea stagnalis $(3,11)$ and Biomphalaria glabrata $(12)$ and that of M. oblongus.

In Aplysia the abdominal ganglion is supplied by small branches that originate directly from the anterior aorta, which may be of strategic importance, given that the majority of neurons involved in cardiovascular regulation are found within it. The location of these neurons permits the monitoring of pressure and chemical indicators of cardiovascular and respiratory functions (1). Like Aplysia, both the visceral ganglion and the subesophageal ganglia of $M$. oblongus receive arterial branches that originate from the anterior aorta. The visceral ganglion performs visceral control functions and thus similar origins and functions for this anatomical organization may be presumed.

In vertebrates, the vascularization of the CNS follows two basic patterns. One consists of a capillary network that originates from isolated vessels that anastomose, and the other from vessels that penetrate the nervous tissue and in the distal portion give rise to capillary loops. In almost all studied vertebrates, these patterns are exclusive. Invertebrates, for the most part, do not have hemolymph vessels within the nervous tissue, though there are some exceptions, such as the squid that has capillary vessels forming a reticular pattern and worms that have a vascular system in the form of capillary loops (13). It appears that there is no correlation between the phylogenetic position of a determined species and the microvascularization pattern of the CNS. Thus, it is difficult to establish a primitive or advanced pattern of organization of the capillary bed present in the CNS. It seems that in the more primitive organisms, such as invertebrates, the vessels do not penetrate the nervous tissue. The presence of this primitive organization in $M$. oblongus was confirmed by both the absence of areas stained by Trypan blue in the CNS and the absence of vascular structures 
in the histological sections.

The absence of vessels within the nerve ganglia raises the following questions. How does the exchange between the circulating fluid and the nerve cells take place? What is the importance of the irrigation of the CNS to the functioning of the CNS ganglia? The most obvious answer to the first question would be interstitial diffusion. The answer to the second would depend upon the degree of interaction and selectivity of the existing exchanges. In the species studied, we found a series of overlaps and projections of the connective sheath around the nervous ganglia. It was noted that these projections were accompanied by hemolymph vessels, suggesting a pattern of vascular loops, though located outside the nervous tissue. These connective sheath projections, accompanied by vessels, allow the distances between the deepest portions of a certain nervous ganglion and the hemolymph vessels to be equivalent to the distance between the capillaries and the surface of the same ganglion. Another important property of this arrangement is the possibility of a larger area of interaction between the nervous tissue and the hemolymph.

In most vertebrates, the endothelial capillary can be characterized by intense alkaline phosphatase activity, with the exception of certain pulmonary and sinusoid endothelial capillaries (14). Alkaline phosphatase activity is an excellent encephalic microvascularization marker, also for mammals and birds. However, it has been noted that the intensity of the reaction is not uniform in the entire vascular network, being higher in the endothelium of the precapillary arterioles and capillaries and lower in the small veins. It is believed that these differences between the levels of alkaline phosphatase reaction in the endothelium of the encephalic vessels of vertebrates may reflect the functions of the specific segments of microvascularization. Ultrastructural studies in mice, rats, cats and humans have demonstrated that in the capillaries the enzymatic activity is located on the luminal side of the plasma membrane of the encephalic capillary endothelial cells. This would suggest that at these sites there is intense dephosphorylation, transphosphorylation, and transport of phosphate ions (15).

In M. oblongus, the alkaline phosphatase reaction was limited to the perineuronal regions of the CNS. This confirmed the lack of vessels inside the nervous tissue in the histological data. However, it was possible to observe alkaline phosphatase activity in the vascular endothelial cells of the dorsal body gland, as well as in some connective sheath vessels of the nervous ganglia. The absence of alkaline phosphatase activity in some connective sheath vessels may be related to the nonexistence or low activity level of the enzyme or perhaps the existence of functional differences between the endothelium present in this invertebrate species and that found in vertebrates. In addition, in vertebrates, this enzyme is probably one of the enzymatic components of the blood-brain barrier (15). At present, some facts point toward the existence of a hemolymph-neuronal barrier in pulmonate gastropods (16), though it is still not clear which tissue elements might be responsible for such a barrier and what the degree of selectivity of such a barrier might be (17).

\section{Acknowledgments}

We are grateful to Antonio G. Severino for technical assistance. 


\section{References}

1. Brownell PH \& Ligman SH (1992). Mechanisms of circulatory homeostasis and response in Aplysia. Experientia, 48: 818-827.

2. Voltzow J (1985). Morphology of the pedal circulatory system of the marine gastropod Busycon contrarium and its role in locomotion. Zoomorphology, 105: 395-400.

3. Bekius R (1972). The circulatory system of Lymnaea stagnalis (L.). Netherlands Journal of Zoology, 22: 1-58.

4. Luchtel DL, Martin AW, Deeyrup-Olsen I \& Boer HH (1997). Gastropoda: Pulmonata. In: Harrison FW (Editor), Microscopic Anatomy of Invertebrates. Vol. 6B (Mollusca II). Wiley-Liss, Inc., New York, 459718.

5. Zancan DM, Nóblega HG, Severino AG \& Achaval M (1994). Acetylcholinesterase distribution in the central nervous system of Megalobulimus oblongus (Gastropoda, Pulmonata). Archives d'Anatomie, d'Histologie, et d'Embryologie Normales et Expérimentales, 75: 7586.

6. Jaeger CP (1961). Action of acetylcholine on the heart of Strophocheilus oblongus. Comparative Biochemistry and Physiology, 4: 30-32.

7. Frizzo MES, Campos R, Severino AG \& Achaval M (1994). The vasculature of the subfornical organ of the turtle Chrysemys dorbigni. Italian Journal of Anatomy and Embryology, 99: 109-121.

8. Gomori G (1952). Microscopic Histochemistry. Principles and Practice. Chicago University Press, Chicago.

9. Pentreath VW \& Cottrell GA (1970). The blood supply to the central nervous system of Helix pomatia. Zeitschrift für Zellforschung und Mikroskopische Anatomie, 111: 160-178.

10. Scott MIH (1939). Estudio anatómico del Borus Strophocheilus lorentzianus op (Doer) (Mol. Pul.). Revista del Museo de La Plata, Sección Zoología, 7: 217-272.

11. Duval A \& Runham NW (1981). The arterial system of six species of terrestrial slug. Journal of Molluscan Studies, 47: 43-52.

12. Basch $P$ (1969). The arterial system of Biomphalaria glabrata (Say). Malacologia, 7: 169-181.

13. Sharrer $E$ (1944). The capillary bed of the central nervous system of certain invertebrates. Biological Bulletin, 87: 52-58.

14. Adams CWM (1965) Neurohistochemistry. Elsevier, Amsterdam, The Netherlands.

15. Vorbrodt AW (1993). Morphological evidence of the functional polarization of brain microvascular endothelium. In: Pardridge WM (Editor), The Blood-brain Barrier: Cellular and Molecular Biology. Raven Press, New York, 137-164

16. Nóblega HG, Rigon F, Faccioni-Heuser MC \& Achaval M (2001). Does it exist a hemolymph neural barrier in the nervous central system of Megalobulimus oblongus (Mollusca, Gastropoda, Pulmonata)? Acta Microscopica, 3 (Suppl C): 99-100 (Abstract).

17. Reineke M (1976). The glial cells of the cerebral ganglia of Helix pomatia L. (Gastropoda, Pulmonata). Cell and Tissue Research, 169. $361-382$. 